\title{
Familial Pure Gonadal Dysgenesis with 46, XY Karyotype in Three Siblings and Gonadoblastoma in the Youngest Sibling
}

\author{
M. Eunice, B. Kulshreshtha, A. Kriplani *, Rima Dada**, S. Agarwal***, \\ K. Kucheria**, A. K. Karak***, S. Datta Gupta*** and A. C. Ammini \\ Department of Endocrinology and Metabolism, *Department of Obstetrics and Gynaecology, \\ **Department of Anatomy, ***Department of Pathology, All India Institute of \\ Medical Sciences, New Delhi 110 029, India
}

KEYWORDS Familial XY Gonadal Dysgenesis. Y Chromosome. Gonadoblastoma. Primary Amenorrhoea

\begin{abstract}
The occurrence of gonadoblastoma in XY phenotypic females has been well documented. This condition may rarely present in a familial form. In this present study, we present a family of 5 siblings born of non-consanguineous parents. Three sisters (age 13,15 and 17 years) with XY karyotype presented with complaints of primary amenorrhoea. They had a normal female phenotype. The younger two brothers were apparently normal. All the three affected siblings have undergone laparoscopic removal of the gonads. The histopathology of gonads in the elder sibling (II 1) revealed ovarian stroma along with rete testes like elements. Bilateral tubes and the gonads of the younger sibling (II 2) showed fallopian tubes (both sides) and a small portion of ovarian stroma. No focus of gonadoblastoma was identified in these two elder siblings. Histopathology of the youngest sibling (II 3) revealed presence of bilateral gonadoblastoma. The occurrence of gonadoblastoma in the youngest sibling of 3 affected XY siblings is unusual.
\end{abstract}

\section{INTRODUCTION}

Pure XY gonadal dysgenesis (Swyer syndrome) is an extremely rare endocrine disorder. This disorder was first identified in a 46, XY male, reared as female due to abnormal testicular differentiation (Swyer 1955). In complete forms, affected individuals lack testicular determination and present streak gonads, well developed mullerian structures, absence of wolffian structures and female external genitalia. Anecdotal case reports of families with XY GD have been described (Sarafoglou and Ostrer 2000). The modes of transmission described in these families include autosomal recessive, autosomal dominant with a variable penetrance and $X$ linked pattern of inheritance. Gonadoblastomas have been reported in about $30 \%$ of patients with 46 XY GD and occurs in both isolated and familial forms. The first study of familial GD with gonadoblastoma was reported in a pair of monozygotic $46 \mathrm{XY}$ twins whose follow-up was complicated by the development

Corresponding author:

Dr. A. C. Ammini, M.D, DM

Professor and Head, Department of Endocrinology and Metabolism, All India Institute of Medical Sciences,

New Delhi-110029, India.

Telephone (Office): 91-11-26593645; Fax: 26589162

Telephone (Home): 91-11-26108336

E-mail: aca433@yahoo.com of renal failure (Frasier et al. 1964). Here we report a family of 5 where three siblings who presented with primary amenorrhoea, had 46 XY DSD. Two brothers were prepubertal and had a normal male phenotype. The youngest of the three siblings was diagnosed to have bilateral gonadoblastoma.

\section{MATERIALS AND METHODS}

Clinical Profile: In a family of 5 siblings born of non-consanguineous parents, three sisters (age 17, 15 and 13 years) presented with complaints of amenorrhoea (Fig. 1). The elder two sisters had a normal female phenotype and were prepubertal. The youngest female sibling had some breast development (B2). The younger brothers were prepubertal and had a normal male phenotype.

Hormonal Profile: Standard RIA procedure was used for estimating the hormonal levels.

Conventional Cytogenetic Analysis: Conventional cytogenetic analysis was done on peripheral blood using standard techniques. Karyotyping was done on G- banded metaphases obtained from 72-hour cultures.

\section{RESULTS AND DISCUSSION}

The clinical and hormonal profile of the three 
Table 1: Clinical and hormonal profile of the affected siblings

\begin{tabular}{lllccccc}
\hline S.No & Age & Ht. $(\mathrm{cms})(U S / L S)$ & Sexualmaturation & LH(U/L) & $F S H(U / L)$ & Karyotype & USG pelvis \\
\hline II 1 & $17 \mathrm{yrs}$ & $155(79 / 86)$ & A1B1P1 & 33.3 & 80.7 & $46, \mathrm{XY}$ & InfantileUterus \\
II 2 & $15 \mathrm{yrs}$ & $156(75 / 81)$ & A1B1P1 & 32 & 42 & $46, \mathrm{XY}$ & InfantileUterus \\
II 3 & $13 \mathrm{yrs}$ & $153(73 / 80)$ & A1B1P1 & 24 & 37 & $46, \mathrm{XY}$ & InfantileUterus \\
\hline
\end{tabular}

I

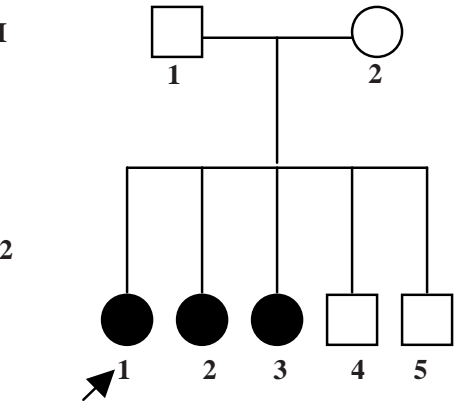

Fig. 1. This pedigree is showing all three affected siblings and normal siblings

sisters is given in Table 1. Cytogenetic analysis revealed 46, XY karyotypes in all the three sisters and two brothers. Figure 2 shows the 46, XY karyotype in the youngest affected sister.

Histopathology: All affected siblings underwent laparoscopic removal of the gonads. The histopathology of the left gonad in the elder sibling revealed ovarian stroma along with rete testes like elements. No seminiferous tubules or primordial follicles were seen. Bilateral tubes and the gonads of the younger sibling (II-2) showed fallopian tubes (both sides) and ovarian stroma. Histopathology of gonads of the youngest sibling (II-3) revealed bilateral gonadoblastoma. The tumor cells were arranged in a nested pattern, the nests being separated by abundant basement membrane-like material. Within the nests, there were two cell types: large cells with clear cytoplasm, similar to those of seminoma, surrounded hyaline nodules, and smaller ones mimicking immature sertoli cells interspersed in between. There was extensive calcification. No Leydig or lutein-like cells could be identified in the multiple sections examined (Fig 3).

\section{DISCUSSION}

XY gonadal dysgenesis usually occurs in
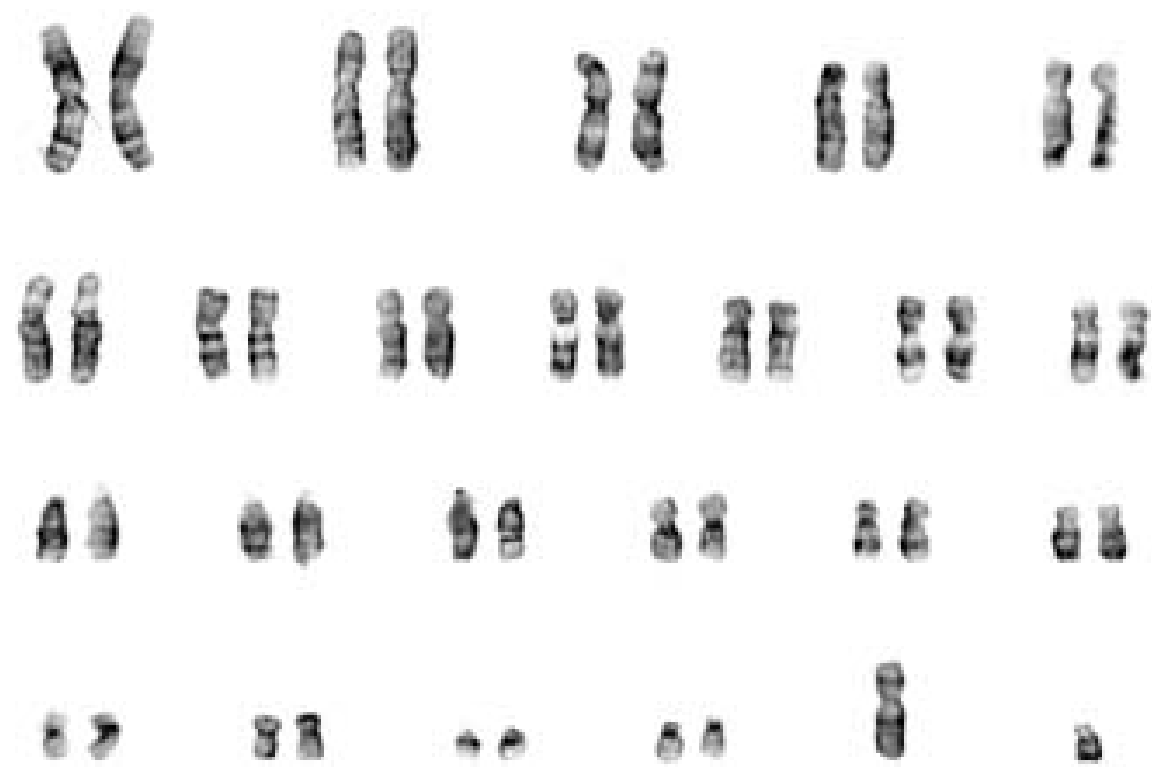

Fig. 2. This figure is showing $46, \mathrm{XY}$ karyotype in the youngest sibling 


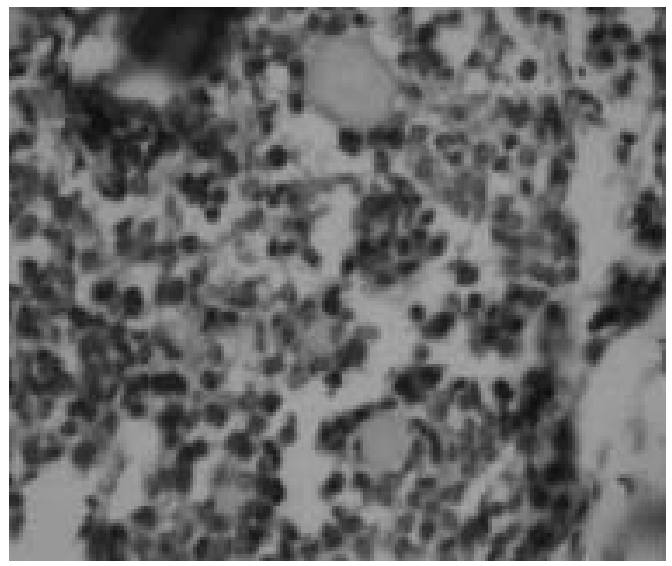

Fig. 3. This photomicrograph of the gonad showing gonadoblastoma (hyaline nodules rimmed by large germ cells. Smaller sertoli-like cells are interspersed in between).

sporadic form. Mutations of the transcription factors involved in gonadal differentiation (testicular determination) have been described. The Y chromosome linked mutations in the SRY protein account for about $10-15 \%$ of cases of gonadal dysgenesis (Harley et al. 2003). Some cases of dysgenetic gonads involve mutations in the autosomal genes like SOX 9 and $W T 1$ and duplication of the $D A X$ gene on $\mathrm{X}$ chromosome (Hanley et al. 2000). The presence of Y chromosome is associated with formation of tumor in dysgenetic gonads. Gonadoblastomas are known to occur with a frequency of $20-30 \%$ in pure XY gonadal dysgenesis (Khalid et al. 1982).

Rarely, XY gonadal dysgenesis may occur in the familial form. Anecdotal reports of families with gonadal dysgenesis with affected siblings and paternal or maternal aunts have been described ( Assumpção et al. 2002; Berg et al. 1989; Mendonça et al. 1994; Sternberg et al. 1968). The reported phenotype in these families with $\mathrm{XY}$ gonadal dysgenesis is diverse ranging from partial to a complete male or female phenotype. Intrafamilial phenotypic heterogeneity has also been described. Assumpcao et al reported a family where $S R Y$ gene mutation was shared by father, two siblings with a partial phenotype (Partial GD), one affected sibling with a female phenotype (Pure GD) and three unaffected male siblings (Assumpção et al. 2002). The heterogeneity of phenotypic presentation within the same family points towards influence of environment or some unknown epigenetic factors that may modify the influence of genes.

Prior to the availability of the detailed genetic testing, careful pedigree analysis demon-strated that this disorder could be inherited in an autosomal recessive pattern or an $\mathrm{X}$ linked pattern. Berg et al described a family where autosomal recessive inheritance was presumed on the basis of $30 \%$ siblings affected by the disorder (Berg et al. 1989). Another interesting description of a family where affected sisters had both a XX and a XY karyotype suggested defect outside X and $\mathrm{Y}$ linkage or an autosomally transmitted defect (Mendonça et al. 1994). History of consanguinity or presence of other somatic abnormalities also point towards an autosomal linkage. Stenberg et al described a family where three different sibships linked by a common maternal linkage were affected (Sternberg et al. 1968; Espiner et al. 1970 ). An X linked inheritance or a sex limited autosomal dominant pattern of inheritance was postulated as causative for dysgenetic gonads in this family. Inheritance of the $\mathrm{Y}$ gene related transcription factors were never considered for transmission to progeny in familial cases of gonadal dysgenesis since affected father would be infertile or sterile. However, one third of the SRY related genetic defects are paternally inherited (Hawkins 1995). Hines et al described a family where the father was mosaic for the SRY gene mutation and had affected females with a XY karyotype (Hines et al. 1997). Molecular defect in the genes regulating sex differentiation, however, may not always explain familial clustering of dysgenetic gonads. Jagger et al described a family with $S R Y$ mutation where the same mutation was shared by an XY female with gonadal dysgenesis, her father, her two brothers and her uncle (Jager et al. 1982). Phenotypic heterogeneity (male-father and females-affected children) in the background of same genotype again points towards unexplained epigenetic mechanisms that could influence the in vivo expression of the genes.

In the present family, XY karyotype was shared by the father, two phenotypically male and three phenotypic female children. Though the present examination of the two male children was normal, one cannot rule out postpubertal gonadal dysfunction in these children. A $60 \%$ (3 of 5 affected children) rate of transmission to the progeny points towards an autosomal dominant mode of inheritance with a variable penetrance. 
Since, there was no other member affected in the previous two generations, it is also possible that father was mosaic for the genetic defect. He possibly transmitted the normal genes to the unaffected siblings and the defect to the affected siblings.

The youngest sibling was diagnosed to have a gonadoblastoma. She presented with some development of breast tissue. The occurrence of gonadoblastoma in the dysgentic gonads is usually asyptomatic. Rarely, hormonal secretion from the tumor may be the cause of medical referral. The breast development is usually because of estradiol secretion from the tumor tissue (Fisher et al. 1982). The formation of gonadoblastoma in the youngest sibling is surprising. Anecdotal case reports of formation of familial gonadoblastoma in XY siblings have been reported ( Kempe et al. 2002; Mann et al. 1983). The heterogenous nature of the course of familial gonadoblastomas has also been described in one family (Kempe et al. 2002). In this family, gonadoblastoma was reported in three maternal aunts of the index case. Gonadoblastoma was surgically removed at the age of 35 years in one aunt who was presently asymptomatic at age 82 years. The other two affected aunts died at a young age of 19 and 20 years due to malignant tumor (Kempe et al. 2002). Another reported family had 5 affected XY members with gonadoblastoma, the youngest XY individual diagnosed at age 6 months (Mann et al. 1983).

In conclusion, this was a rare familial presentation of XY gonadal dysgenesis. The clinical course was complicated by the development of gonadoblatomas in the youngest sibling.

\section{REFERENCES}

Assumpcão JG, Benedetti CE, Maciel-Guerra AT, Guerra G Jr, Baptista MT, Scolfaro MR, de Mello MP 2002. Novel mutations affecting SRY DNA-binding activity: The HMG box $\mathrm{N} 65 \mathrm{H}$ associated with $46, \mathrm{XY}$ pure gonadal dysgenesis and the familial nonHMG box R30I associated with variable phenotypes. J Mol Med, 80(12): 782-790.

Berg FD, Kurzl R, Hinrichsen MJ, Zander J 1989. Familial 46, XY pure gonadal dysgenesis and gonadoblastoma/dysgerminoma: Case report. Gynecol Oncol, 32: 261-267.

Espiner EA, Veale AM, Sands VE, Fitzgerald PH 1970. Familial syndrome of streak gonads and normal male karyotype in five phenotypic females. $N$ Engl $J$ Med, 283: 6-11.

Fisher RA, Salm R, Spencer RW 1982. Bilateral gonadoblastoma/dysgerminoma in a $46 \mathrm{XY}$ individual: Case report with hormonal studies. J Clin Pathol, 35(4): 420-424.

Frasier SD, Bashore RA, Mosier HD. 1964. Gonadoblastoma associated with pure gonadal dysgenesis in monozygous twins. J Pediatr, 64: 740-745.

Hanley NA, Hagan DM, Clement-Jones M, Ball SG, Strachan T, Salas-Cortés L,McElreavey K, Lindsay S, Robson S, Bullen P, Ostrer H, Wilson DI 2000. $S R Y, S O X 9$, and DAX1 expression patterns during human sex determination and gonadal development. Mech Dev, 1;91 (1-2): 403-407.

Harley VR, Clarkson MJ, Argentaro A 2003. The molecular action and regulation of the testisdetermining factors, SRY (sex-determining region on the Y chromosome) and SOX9 [SRY-related high-mobility group (HMG) box 9]. Endocr Rev, 24(4): 466-487.

Hawkins JR 1995. Genetics of XY sex reversal. $J$ Endocrinol, 147: 183-187.

Hines RS, Tho SP, Zhang YY, Plouffe L Jr, Hansen KA, Khan I, McDonough PG 1997. Paternal somatic and germ-line mosaicism for a sex-determining region on Y (SRY) missense mutation leading to recurrent 46, XY sex reversal. Fertil Steril, 67: 675679.

Jager RJ, Harley VR, Pfeiffer RA, Goodfellow PN, Scherer G 1992 A familial mutation in the testisdetermining gene SRY shared by both sexes. Hum Genet, 90: 350-355.

Kempe A, Engels H, Schubert R, Meindl A, van der Ven K, Plath H, Rhiem K, Schwanitz G, Schmutzler RK 2002. Familial ovarian dysgerminomas (Swyer syndrome) in females associated with $46 \mathrm{XY}$ karyotype. Gynecol Endocrinol, 16(2): 107-111.

Khalid BA, Bond AG, Ennis G, Medley G. 1982. Dysgerminoma-gonadoblastoma and familial 46XY pure gonadal dysgenesis: case report and review of the genetics and pathophysiology of gonadal dysgenesis and $\mathrm{H}-\mathrm{Y}$ antigen. Aust N Z J Obstet Gynaecol, 22(3): 175-179.

Mann JR, Corkery JJ, Fisher HJ, Cameron AH, Mayerová A, Wolf U, Kennaugh AA, Woolley V 1983 Familial ovarian dysgerminomas (Swyer syndrome) in females associated with $46 \mathrm{XY}$-karyotype. $J$ Med Genet, 20: 264-270.

Mendonça BB, Barbosa AS, Arnhold IJ, McElreavey K, Fellous M, Moreira-Filho CA 1994. Gonadal agenesis in $\mathrm{XX}$ and $\mathrm{XY}$ sisters: evidence for the involvement of an autosomal gene. Am J Med Genet, 152(1): $39-43$.

Sarafoglou K, Ostrer H 2000. Clinical review 111: familial sex reversal: a review. J Clin Endocrinol Metab, 85(2): 483-493.

Sternberg WH, Barklay DL, Kloepfer W 1968. Familial XY gonadal dysgenesis. N Engl J Med, 278: 695700 . 